\title{
Positive effects of a cognitive-behavioral intervention program for family caregivers of demented elderly
}

\author{
Efeitos positivos de um programa de intervenção cognitivo-comportamental para \\ cuidadores familiares de idosos com demência
}

Patrícia Paes Araujo Fialho 1,3, Anne Marise Köenig'2,3, Maria Dolores Lemos dos Santos ${ }^{3}$, Maira Tonidandel Barbosa $^{4,5}$, Paulo Caramelli, 1,3

\begin{abstract}
Objective: It was to examine the effects of a Cognitive-Behavioral Therapy (CBT) program administered to family caregivers of dementia patients. Methods: Forty family caregivers were enrolled in a CBT intervention across eight weekly sessions. Cognitive, functional and behavioral status of patients were evaluated, as well as their own and their family caregivers' perceptions of quality of life. Specific instruments were also applied to evaluate caregiver stress level, coping, anxiety and depression. Results: At the end of the program, family caregivers reported fewer neuropsychiatric symptoms among patients and an improvement in patients' quality of life. In addition, caregivers changed their coping strategies, whereas a significant decrease was observed in their anxiety levels. Conclusion: The CBT program employed appears to be a promising and useful tool for clinical practice, displaying positive effects on quality of life and neuropsychiatric symptoms of dementia, as well as proving beneficial for alleviating anxiety and stress in family caregivers.
\end{abstract}

Key words: anxiety, depression, quality of life, stress.

\section{RESUMO}

Objetivo: Foi analisar os efeitos de um programa de intervenção de Terapia Cognitivo-Comportamental (TCC) administrado a cuidadores familiares de pacientes com demência. Métodos: Foram incluídos 40 cuidadores familiares que participaram do programa durante oito sessões semanais. Foi avaliado o perfil cognitivo, funcional e comportamental dos pacientes, bem como sua qualidade de vida e de seus cuidadores familiares. Foram utilizados instrumentos específicos para a avaliação do nível de estresse do cuidador, estilos de enfrentamento (coping), ansiedade e depressão. Resultados: Ao final do programa, os cuidadores familiares relataram diminuição dos sintomas neuropsiquiátricos nos pacientes e aumento da qualidade de vida deles. Observou-se ainda mudança no estilo de coping dos cuidadores e diminuição significativa do nível de ansiedade. Conclusão: O Programa de TCC mostrou-se instrumento útil e promissor para a prática clínica, revelando efeitos positivos na qualidade de vida e nos sintomas neuropsiquiátricos da demência, bem como promovendo alívio da ansiedade e do estresse dos cuidadores familiares.

Palavras-Chave: ansiedade, depressão, qualidade de vida, estresse.

Dementia is usually chronic and progressive, deteriorating patients' autonomy and rendering them increasingly dependent on others. In addition, Behavioral and Psychological Symptoms of Dementia (BPSD) reduce patients', families' and caregivers' quality of life (QoL) and represent one of the most important reasons for institutionalization ${ }^{1,2}$.
There is a growing body of literature about the benefits of intervention programs for caregivers. Mittelman ${ }^{3}$ showed that family counseling and support group meetings reduced nursing home placements and also improved caregiver mental and physical health. Additionally, Hinchliffe ${ }^{4}$ revealed that a multidisciplinary approach, combining medication,

\footnotetext{
${ }^{1}$ Programa de Pós-graduação em Neurociências, Universidade Federal de Minas Gerais (UFMG), Belo Horizonte MG, Brazil;

${ }^{2}$ Curso de Terapia Ocupacional, Universidade Federal do Triângulo Mineiro (UFTM), Uberaba MG, Brazil;

${ }^{3}$ Ambulatório de Neurologia Cognitiva e do Comportamento, Hospital das Clínicas da UFMG, Belo Horizonte MG, Brazil;

${ }^{4}$ Programa de Pós-graduação em Geriatria, Hospital Mater Dei e Faculdade de Ciências Médicas de Minas Gerais (FCMMG), Belo Horizonte MG, Brazil;

${ }_{5}^{5}$ Departamento de Clínica Médica, Faculdade de Medicina da UFMG, Belo Horizonte MG, Brazil.

Correspondence: Paulo Caramelli; Departamento de Clínica Médica, Faculdade de Medicina da Universidade Federal de Minas Gerais; Avenida Prof. Alfredo Balena 190 / sala 246; 30130-100 Belo Horizonte MG - Brasil; E-mail: caramelli@ufmg.br

Support: Paulo Caramelli, MD, PhD, is funded by the Conselho Nacional de Desenvolvimento Científico e Tecnológico (CNPq) and Fundação de Amparo à Pesquisa do Estado de Minas Gerais (FAPEMIG), Brazil.

Conflict of interest: There is no conflict of interest to declare.
}

Received 27 May 2012; Received in final form 05 June 2012; Accepted 12 June 2012 
psychological techniques and social measures, improved caregivers' mental health and problematic behaviors of dementia patients. In fact, many intervention programs have proven effective for reducing burden and depression among caregivers ${ }^{3,5-7}$. In this regard, Cognitive-Behavioral Therapy (CBT) appears to be particularly effective for decreasing depressive symptoms ${ }^{8}$.

The 10/66 Dementia Research Group brief caregiver intervention 'Helping Carers to Care' was developed using the available resources in place ${ }^{9}$. The first two trials, from India ${ }^{10}$ and from Russia ${ }^{11}$, showed this intervention to be feasible and acceptable, leading to improvements in mental health care providers and their responsibilities in care practice. A third study in Peru ${ }^{12}$ showed a significant reduction in caregiver role strain, confirming similar results of interventions used in developed countries. Finally, a Brazilian study ${ }^{13}$ was conducted comparing psychosocial characteristics, QoL and caregiver overload between dementia caregivers and a control group. The authors found that the caregiver discussion group was beneficial to its participants, also with positive effects on patients, particularly regarding QoL.

The relative paucity of non-pharmacological interventions including family caregivers, especially in developing countries, points to the importance of conducting studies such as the present investigation, aiming to investigate the effects of a CBT program on family caregivers of patients with dementia.

\section{METHODS}

\section{Participants}

Forty family caregivers and their relatives with dementia that met the inclusion criteria participated in the study.

Inclusion criteria for the caregivers were: being relatives (first degree or spouses/husbands); age greater than or equal to 21 years; education greater than or equal to 4 years; spend at least 24 weekly hours with patient; being available to come to all meetings; and not being a professional caregiver. Regarding patients, they had to meet DSM-IV ${ }^{14}$ criteria for dementia and to be on a stable drug regimen for at least 30 days.

\section{Measures}

The global cognitive, functional and behavioral patients profiles were built based on the Brazilian versions of the Mini-Mental State Examination (MMSE) ${ }^{15}$, the Disability Assessment for Dementia (DAD) ${ }^{16}$ and the Neuropsychiatric Inventory (NPI) ${ }^{17}$, respectively. QoL was assessed using the QoL scale for patients with Alzheimer's disease and their caregivers (QoL-AD, family answered questionnaire only) ${ }^{18,19}$.

Caregivers were also assessed regarding their own perception of QoL and answered the section of the QoL-AD related to the QoL of caregivers. Burden related to care activity level, stress and anxiety were evaluated by the Zarit Caregiver
Burden Interview $(\mathrm{ZBI})^{20}$, the List of Stress Symptoms (LSS) ${ }^{21}$ and both the Jalowiec Coping Scale (JCS) ${ }^{22}$ and trait anxiety scale (A-trait) of the State Trait Anxiety Inventory (STAI) ${ }^{23}$, respectively. Caregivers were also evaluated for depression using the Major Depressive Episode module of the Mini International Neuropsychiatric Interview (MINI) 5.0. (DSM-IV) ${ }^{24}$.

\section{The MMSE ${ }^{15}$ was used for global cognitive assessment of patients.}

The DAD Scale ${ }^{16}$ assesses what the individual/patient is effectively able to do without help or without being reminded by the caregiver. The DAD comprises 40 items: 17 related to basic self-care and 23 to instrumental activities. Leisure activities are assessed in terms of the interest shown in these activities. Each of the 40 items is scored as: (i) Yes (1 point) - the person performed the activity without help or reminders in the last two weeks even if having done so only once; (ii) No (0 points) - the person was unable to perform the activity without help or reminder in the last two weeks; and (iii) N/A - "not applicable" (0 points) - the person never performed the activity before disease onset nor had the opportunity to do so in the last two weeks. Total score is obtained by summing the points for each item and converting the total value into a percentage (DAD\%). Items classified as N/A are not included in the total score. The score represents overall functional performance on activities of daily living. Higher scores represent better functional performance, while lower scores indicate greater dysfunction.

The $\mathrm{NPI}^{17}$ evaluates neuropsychiatric disorders commonly found in dementia. It comprises a questionnaire assessing 12 behavioral domains. The total score for each domain is calculated by multiplication of frequency versus intensity. Finally, the items are summed to give a total score; higher scores indicate worst neuropsychiatric profile.

The QoL-AD ${ }^{18,19}$ consists of 13 indicators of QoL quantified on a scale of one to four (poor, fair, good and excellent), with 1 denoting poor and 4, excellent. Total QoL-AD scores range from 13 to 52 points; greater scores indicate better QoL. The scale has both patient and caregiver versions.

The $\mathrm{ZBI}^{20}$ comprises 22 questions with responses ranging from 0 (never) to 4 (almost always). The scale reflects caregiver perception of health, personal and social life, financial situation, personal well-being and interpersonal relationships. Finally, the caregiver must rate to what extent they feel overwhelmed by the care. The total sum of the items ranges from 0 to 88 ; higher scores indicate greater level of burden.

The LSS $^{21}$ is a list of 59 psychophysiological and psychosocial stress symptoms which the subject scores according to the frequency of occurrence: (0) never, (1) few times, (2) often or (3) always. The total sum of responses indicates the stress level of the individual; higher scores indicate greater level of stress. Maximum score on the LSS is 177 points.

The JCS ${ }^{22}$ consists of 60 items that describe cognitive and behavioral efforts adopted as part of stress-coping strategies. 
Items are grouped into eight dimensions randomly distributed, and the respondent is oriented to select those behaviors which they most identify with when facing a problem. The confrontational, evasive, supportive and self-reliant strategies comprise a problem-focused coping style, while optimistic, fatalistic, emotive and palliative strategies encompass an emotion-focused coping style.

The $\mathrm{STAI}^{23}$ consists of 20 statements used by individuals to describe how they generally feel. The score varies according to how often these statements apply: (1) almost never, (2) sometimes, (3) often and (4) almost always. Possible scores on the STAI range from 20 to 80 ; higher scores indicate greater anxiety levels.

The Major Depressive Episode module is part of the MINI $(\mathrm{DSM}-\mathrm{IV})^{14}$ and aims to verify the presence of depression over a given time frame.

All assessments, except for the MMSE, whose results were collected from patients' medical files and correspond to the date of the patient's last visit prior to joining the group, were performed by one neuropsychologist (PPAF) and two occupational therapists (AMK and MDLS). The evaluators were previously trained to uniformly apply the tests and scales. NPI and STAI were applied to all patients by the neuropsychologist (PPAF).

\section{Intervention}

The intervention was based on CBT techniques, more specifically Training of Social Skills (TSS) which in Goldsmith and McFall's view seeks to increase the competence of performance in critical situations of life, i.e. the acquirement of a new repertoire of responses ${ }^{25}$. Thus, the program encompasses several techniques including: (a) information/statement - understanding the problem, information and behavioral targeting (education); (b) skills training (cognitive, emotional and social) - teaching specific behaviors that are applied and integrated into the subject's behavior repertoire; (c) support/empathy - extends perception and enhances the ability to put oneself in the place of another; (d) social comparison - vicarious learning by pre-specified models, a shared sense of reality; (e) self-governance, self-instruction - teaching strategies to control or modify own behavior, through the use of different situations in order to achieve long-term goals and use of the internal language as a way of guiding behavior; (f) referential reinforcement - fostering of persistence and effort; (g) cognitive strategies - self-monitoring and reallocation of efforts; (h) diary/therapy schedule - self referencing, evaluation and understanding of changes; (i) activity organization and prior preparation (anticipation of events).

The program consisted of eight weekly sessions each lasting two hours. The techniques listed above were employed during the sessions on information and group discussion. In some sessions, a home task was set for the caregivers. According to Caballo $^{25}$, these tasks are the vehicle through which the skills learned in each session are practiced in the real environment, i.e. generalized to the daily life of the participant.

The intervention was conducted by a neuropsychologist (PPAF) and two occupational therapists (AMK and MDLS). The neuropsychologist was responsible for providing clinical information related to dementia, counseling and support interventions, as well as for training on cognitive-behavioral strategies. The occupational therapists were responsible for interventions aimed at promoting daily life activities.

\section{Statistical analysis}

Data were analyzed with SPSS statistical package for Windows, version 18.0. The representativeness of the sample was checked using Bootstrap re-sampling technique. Comparison of the incidence of depression before and after intervention was done by drawing up a contingency table (MINI before the Group versus MINI after the Group). The matched data were analyzed using McNemar's test. Paired $t$-tests were performed to provide a comparative analysis of the evaluations done before and after the intervention. Principal Components Analysis (PCA) with Varimax rotation was employed to select those variables which made the greatest contribution to the breakdown of changes assessed pre- and post-group. Models of analysis of variance (ANOVA) were calculated to assess the effects of income related issues, time as caregiver, hours per week spent with the patient by caregiver and information about dementia, on the results of the response variables extracted by PCA (difference between before and after the intervention). A significance level of $5 \%$ $(\alpha=0.05)$ was adopted for the analysis of the results obtained. Similarly, all confidence intervals (CI) were built based on a confidence level of $95 \%$.

\section{Ethics}

The research project was approved by the Ethics Committee of the Universidade Federal de Minas Gerais, Belo Horizonte, Brazil. All caregivers, and patients whenever possible, signed a written informed consent.

\section{RESULTS}

\section{Sample characteristics}

Overall, 10 groups with a total of 45 caregivers of elderly patients with dementia were enrolled. However, 5 participants were subsequently excluded from the analysis because they failed to complete the full intervention program or its assessments. Therefore, the final analysis included results from 40 caregivers and 39 patients (one patient had two relatives taking part in the study, whom fulfilled the inclusion criteria for caregivers).

Mean age and educational level of participants, as well as gender distribution, are depicted in Table 1. Only four men 
participated in the intervention. There was a wide variation in age and schooling of participants.

Twenty-eight patients (70\%) had probable Alzheimer's disease $(\mathrm{AD})^{26}$, six (15\%) had $\mathrm{AD}$ with cerebrovascular disease $^{27}$, while the six remaining cases had other diagnoses (frontotemporal dementia, progressive supranuclear palsy, alcoholic dementia, dementia with Lewy bodies, dementia caused by head trauma and dementia associated with Parkinson's disease). The average time of clinical course after the diagnosis of dementia was $3.3 \pm 3.8$ years.

Table 2 presents the cognitive, functional and behavioral data of dementia patients before the intervention program. In general, patients had moderate cognitive impairment, with significant behavioral changes and low level of functionality.

\section{Effects of caregiver interventions}

Only one caregiver from a total of six who fulfilled DSM-IV diagnostic criteria for Major Depressive Episode before the group sessions persisted with this diagnosis post-intervention. However, this positive effect on caregiver mood did not reach statistical significance $(p=0.063)$.

Table 3 shows the descriptive statistics of the instruments used. NPI, QoL patient, JCS coping factors and STAI (A-trait) scores showed significant differences after the intervention in comparison to baseline.

The PCA method with Varimax rotation was used to select those variables which most contributed to the discrimination of changes assessed pre- and post-group. Five key components explained $64.4 \%$ of total variation excerpts, namely: Key component 1 - JCS Optimistic, JCS Self-reliant, JCS problem-focused coping; Key component 2 - ZBI; Key component 3 - DAD - total percentage (DAD\%) and A-Trait anxiety scale; Key component 4 - QoL-Caregiver; Key component 5 - JCS Fatalistic. Selected variables were compared for demographics and caregiver responses to the questionnaire.

Regarding the $t$-test analysis, data on caregivers not receiving help from relatives or others (sole caregivers) and from the dialogue with doctors about patients' diagnoses and degree of kinship (only the children or spouses of patients as caregivers, in this case, $\mathrm{n}=36$ ) are given in Table 4. Sole caregivers were more optimistic after the intervention ( $\mathrm{p}=0.046)$. They also began to focus more attention on the problem when resolving difficult situations, while avoiding emotion interference $(\mathrm{p}=0.016)$. In the case of caregivers who talked to the doctor about the diagnosis of their relative, the tendency was to focus more on the problem when they needed to tackle it $(\mathrm{p}=0.024)$. Finally, daughters/sons caring for parents with dementia were less anxious after the intervention than spouses $(\mathrm{p}=0.037)$. No significant difference in scores among caregivers was observed for other questionnaire variables (DAD\%, LSS and JCS Fatalistic).

ANOVA models were calculated to assess the effects of income, time as caregivers, hours per week spent with the patient and information about dementia contained in the selected instruments from the PCA. Comparisons yielded significant differences according to the analysis of variance performed: (a) income of caregivers and scores obtained on QoL Caregiver and LSS ( $\mathrm{p}=0.008$ for both); (b) time as

Table 1. Descriptive analysis of variables age, schooling and gender with Bootstrap Confidence Interval for mean and proportion.

\begin{tabular}{|c|c|c|c|c|c|c|c|c|c|}
\hline & & \multirow[t]{2}{*}{$\mathrm{n}$} & \multirow{2}{*}{ Minimum } & \multirow{2}{*}{ Maximum } & \multirow{2}{*}{$\begin{array}{l}\text { Mean/ } \\
\text { Frequency }\end{array}$} & \multirow[t]{2}{*}{$\mathrm{SD}$} & \multirow{2}{*}{ Median } & \multicolumn{2}{|c|}{$\begin{array}{c}95 \% \mathrm{Cl} \\
\text { Bootstrap to the mean }\end{array}$} \\
\hline & & & & & & & & Lower limit & Upper limit \\
\hline \multirow{2}{*}{ Age } & Caregiver & 40 & 29 & 75 & 54.4 & 11.2 & 53 & 48.9 & 57.8 \\
\hline & Patient & 39 & 49 & 91 & 76.0 & 9.8 & 76 & 71.1 & 78.7 \\
\hline \multirow{2}{*}{ Education } & Caregiver & 40 & 3 & 22 & 8.7 & 4.2 & 8 & 6.7 & 9.3 \\
\hline & Patient & 39 & 0 & 21 & 4.8 & 4.6 & 4 & 2.7 & 6.3 \\
\hline \multirow{2}{*}{ Gender } & Caregiver & 40 & - & - & $90.0 \%$ fem. & - & - & 88.9 & 100.0 \\
\hline & Patient & 39 & - & - & $51.3 \%$ fem. & - & - & 33.3 & 70.4 \\
\hline
\end{tabular}

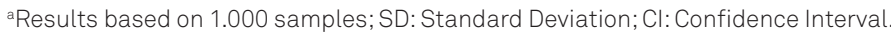

Table 2. Descriptive analysis of results on Mini-Mental State Examination, neuropsychiatric inventory and disability assessment for dementia scales for patients (with Bootstrap Confidence Interval for mean)a.

\begin{tabular}{|c|c|c|c|c|c|c|c|c|}
\hline \multirow{2}{*}{ Instruments } & \multirow{2}{*}{ MMSE } & \multirow{2}{*}{ NPI } & \multicolumn{6}{|c|}{ DAD } \\
\hline & & & 1 & $\mathrm{PO}$ & $\mathrm{AE}$ & NA & Total & Total (\%) \\
\hline Mean & 10.84 & 22.65 & 7.15 & 3.60 & 7.25 & 3.23 & 18.00 & 47.92 \\
\hline Standard Deviation & 9.43 & 22.29 & 3.66 & 3.22 & 4.56 & 6.80 & 10.81 & 27.88 \\
\hline Median & 12 & 15 & 8 & 3 & 7 & 1 & 19 & 49.36 \\
\hline \multicolumn{9}{|l|}{ Percentiles } \\
\hline 5 & 0.00 & 3.05 & 0.00 & 0.00 & 0.05 & 0.00 & 0.15 & 0.37 \\
\hline 25 & 0.00 & 8.25 & 5.00 & 0.25 & 3.00 & 0.00 & 8.50 & 23.81 \\
\hline 75 & 19.43 & 30.50 & 10.00 & 5.75 & 10.75 & 4.00 & 24.75 & 67.29 \\
\hline 95 & 25.90 & 71.80 & 13.00 & 9.95 & 15.00 & 17.60 & 36.90 & 94.86 \\
\hline
\end{tabular}

a:Results based on 1.000 samples; I: Initiative; PO: Planning and Organization; AE: Achieving Effectiveness; NA: responses to "not applicable"; MMSE: MiniMental State Examination; NPI: neuropsychiatric inventory; DAD: Disability Assessment for Dementia. 
caregiver and scores obtained on JCS problem-focused coping $(\mathrm{p}=0.030)$; and $(\mathrm{c})$ information on dementia and scores obtained on QoL Caregiver ( $\mathrm{p}=0.044)$.

Bonferroni's method for Multiple Comparisons of Means revealed that: (a) QoL increased more in caregivers with no income compared to caregivers with more than three minimum wages $(\mathrm{p}=0.006)$. Caregivers with no income also showed greater stress symptoms' reduction compared to those with incomes between one and three minimum wages $(p=0.013)$; (b) individuals with three to five years of experience as caregivers tended to deal with difficult situations by addressing the problem to a greater degree than those with more than five years of experience ( $p=0.048)$; (c) QoL increased more in caregivers who had no information than in those who sought information through reading and internet $(\mathrm{p}=0.040)$.
Finally, Table 5 shows linear regression models adjusted to the following criteria: DAD\% variables, QoL Caregiver and JCS Optimistic. Models involving other instruments (LSS, JCS Fatalistic, JCS Problem-focused coping and A-trait) also selected in the PCA procedure did not provide meaningful relationships with the studied predictor variables. The stepwise technique was used with all sociodemographic variables and with caregiver prior knowledge obtained from questionnaire responses.

\section{DISCUSSION}

In this study, a CBT intervention program was administered to a group of 40 family caregivers of dementia patients in a total of 8 weekly sessions.

Table 3. Descriptive analysis and paired t-test with Bootstrap Confidence Interval for mean of variables on Neuropsychiatric Inventory, Zarit Caregiver Burden Interview, quality of life, List of Stress Symptoms, Jalowiec Coping Scale and A-trait scales.

\begin{tabular}{|c|c|c|c|c|c|c|c|c|}
\hline \multirow[t]{2}{*}{ Instruments } & & \multicolumn{2}{|c|}{ Before Group } & \multicolumn{2}{|c|}{ After Group } & \multirow[t]{2}{*}{$p$-value } & \multicolumn{2}{|c|}{$\begin{array}{l}95 \% \mathrm{Cl} \\
\text { Bootstrap to the average }\end{array}$} \\
\hline & & Mean & SD & Mean & SD & & Lower limit & Upper limit \\
\hline NPI & & 22.65 & 22.29 & 17.28 & 15.31 & 0.034 & 1.174 & 10.288 \\
\hline $\mathrm{ZBI}$ & & 32.53 & 14.53 & 30.40 & 14.78 & 0.187 & -0.862 & 5.224 \\
\hline \multirow{2}{*}{ QoL } & Caregiver & 35.73 & 5.39 & 36.48 & 6.29 & 0.452 & -2.683 & 1.343 \\
\hline & Patient & 29.98 & 6.87 & 31.93 & 5.54 & 0.040 & -3.807 & -0.300 \\
\hline \multicolumn{2}{|l|}{ LSS } & 49.62 & 28.20 & 49.79 & 21.93 & 0.965 & -6.514 & 5.848 \\
\hline \multirow{10}{*}{$\begin{array}{l}\text { JCS } \\
\text { (Coping - } \\
\text { factors) }\end{array}$} & Confrontational & 6.67 & 2.27 & 7.78 & 1.86 & 0.011 & -1.912 & -0.399 \\
\hline & Evasive & 4.80 & 2.92 & 4.86 & 1.55 & 0.902 & -1.029 & 0.909 \\
\hline & Optimistic & 6.10 & 1.58 & 6.72 & 1.57 & 0.080 & -1.329 & 0.017 \\
\hline & Fatalistic & 1.49 & 1.14 & 0.91 & 0.79 & 0.001 & 0.257 & 0.900 \\
\hline & Emotive & 2.02 & 1.26 & 1.64 & 0.98 & 0.070 & 0.004 & 0.757 \\
\hline & Palliative & 1.90 & 1.51 & 2.36 & 1.74 & 0.139 & -1.129 & 0.104 \\
\hline & Supportive & 3.59 & 1.11 & 3.56 & 1.03 & 0.881 & -0.472 & 0.441 \\
\hline & Self-reliant & 4.18 & 1.92 & 4.72 & 1.68 & 0.172 & -1.272 & 0.193 \\
\hline & Coping problem & 19.90 & 5.06 & 21.18 & 3.40 & 0.227 & -3.243 & 0.610 \\
\hline & Coping emotion & 10.76 & 3.50 & 12.33 & 2.82 & 0.011 & -2.822 & -0.466 \\
\hline A-trait & & 45.62 & 10.78 & 40.59 & 10.43 & 0.005 & 1.892 & 8.046 \\
\hline
\end{tabular}

${ }^{a}$ Results based on 1.000 samples. NPI: Neuropsychiatric Inventory; QoL: quality of life; JCS: Jalowiec Coping Scale; ZBI: Zarit Caregiver Burden Interview; LSS: List of Stress Symptoms; CI: Confidence Interval; SD: Standard Deviation. *Significant differences at level of $5 \%$.

Table 4. Comparison of means (before and after Group) with Student's t-test for independent groups on demographic issues and questionnaire.

\begin{tabular}{|c|c|c|c|c|c|c|}
\hline \multirow{2}{*}{\multicolumn{2}{|c|}{ Equal variance assumed }} & \multirow{2}{*}{$\begin{array}{l}\text { Mean } \\
\text { difference }\end{array}$} & \multirow{2}{*}{$\mathrm{p}$-value } & \multicolumn{2}{|c|}{$\begin{array}{l}95 \% \mathrm{Cl} \\
\text { for mean difference } \\
\end{array}$} & \multirow{2}{*}{ Interpretation } \\
\hline & & & & $\begin{array}{l}\text { Lower } \\
\text { limit }\end{array}$ & $\begin{array}{l}\text { Upper } \\
\text { limit }\end{array}$ & \\
\hline JCS Optimistic & Sole caregiver & 1.281 & 0.046 & 0.149 & 2.574 & $\begin{array}{l}\text { Significant. Score of JCS Optimistic increased in } \\
\text { caregivers not receiving help from others. }\end{array}$ \\
\hline \multirow[b]{2}{*}{$\begin{array}{l}\text { JCS Coping focused } \\
\text { on problem }\end{array}$} & Sole caregiver & 4.897 & 0.016 & 1.210 & 8.379 & $\begin{array}{l}\text { Significant. Score of JCS Problem-focused coping } \\
\text { rose in caregivers not receiving help from others. }\end{array}$ \\
\hline & $\begin{array}{l}\text { Dialogue with } \\
\text { doctor }\end{array}$ & 4.435 & 0.024 & 8.125 & 0.737 & $\begin{array}{c}\text { Significant. Score of JCS Problem-focused } \\
\text { coping increased for those who had dialogue } \\
\text { with doctor. }\end{array}$ \\
\hline A-trait & Degree of kinship & 7.310 & 0.037 & 0.725 & 13.612 & $\begin{array}{l}\text { Significant. The A-trait decreased more in the } \\
\text { children than in spouses of patients. }\end{array}$ \\
\hline
\end{tabular}

Results based on 1.000 samples. JCS: Jalowiec Coping Scale; Cl: Confidence Interval. 
Table 5. Regression models of variable criterion: Disability Assessment for Dementia\%, Zarit Caregiver Burden Interview, quality of life caregiver, Jalowiec Coping Scale Optimistic, Jalowiec Coping Scale Fatalist and A-trait.

\begin{tabular}{|c|c|c|c|c|c|c|c|}
\hline \multirow{2}{*}{$\begin{array}{l}\text { Variable response } \\
\text { (difference*) }\end{array}$} & \multirow[b]{2}{*}{ Variable } & \multirow{2}{*}{$\begin{array}{l}\text { Coefficients } \\
\text { (Beta values) }\end{array}$} & \multirow[b]{2}{*}{ T-Statistic } & \multirow[b]{2}{*}{$\mathrm{p}$-value } & \multicolumn{2}{|c|}{$\mathrm{Cl}$ of coefficient } & \multirow[b]{2}{*}{ Interpretation } \\
\hline & & & & & $\begin{array}{l}\text { Lower } \\
\text { limit }\end{array}$ & $\begin{array}{l}\text { Upper } \\
\text { limit }\end{array}$ & \\
\hline \multirow{2}{*}{ DAD\% } & Constant & 33.412 & 4.241 & 0.000 & 17.463 & 49.362 & \multirow{3}{*}{$\begin{array}{l}\text { Higher income related to higher level } \\
\text { of functionality/independence. }\end{array}$} \\
\hline & Income & 14.507 & 2.179 & 0.036 & 1.028 & 27.987 & \\
\hline \multirow{3}{*}{ QOL caregiver } & Constant & 15.081 & 3.697 & 0.001 & 6.815 & 23.346 & \\
\hline & Income & -4.085 & -3.199 & 0.003 & -6.673 & -1.498 & \multirow[t]{2}{*}{$\begin{array}{l}\text { Higher income and greater age } \\
\text { related to lower quality of life. }\end{array}$} \\
\hline & Age of caregiver & -0.188 & -2.566 & 0.014 & -0.337 & -0.040 & \\
\hline JCS Optimistic & Degree of Kinship & 0.366 & 2.106 & 0.042 & 0.015 & 0.718 & $\begin{array}{c}\text { Child relates positively with factor of } \\
\text { coping optimistic. }\end{array}$ \\
\hline
\end{tabular}

*Only instruments for assessment of caregiver. Cl: Confidence Interval; DAD: Disability Assessment for Dementia; ZBI: Zarit Caregiver Burden Interview; QoL: quality of life; JCS: Jalowiec Coping Scale.

A larger effect was observed in relation to anxiety level, which decreased significantly after two months of weekly group meetings. Depression was present in fewer caregivers post-intervention, and, although this change was not significant, a statistical trend toward reduced depression after the group intervention was identified. Results also highlighted a significant decrease in behavioral changes in the elderly with dementia, as well as a perception of higher QoL by these individuals. It is highly likely that less anxious caregivers are more able to take care of patients and to perceive the environmental elements or behaviors that promote the expression of BPSD. Moreover, caregivers were more tolerant, while some no longer felt overwhelmed by depression and, thus, may have increased their tolerance threshold to BPSD. Hence, even if these changes do manifest, they do not cause great anxiety.

Although the caregivers still had high scores on ZBI and LSS scales after the intervention, their QoL perception increased, despite not reaching statistical significance. It is likely that the duration of the intervention was too short to lead to more significant changes.

One of the most significant changes pertained to how caregivers dealt with the stressful situations of life (beyond the context of caring for a family member with dementia). According to Lazarus and Folkman ${ }^{28}$, the way we perceive and deal with problems influences our well-being. These authors described two major coping strategies: "problemfocused coping" and "emotion-focused coping". People use both coping styles in stressful situations. Corroborating this view, both coping strategies had increased scores after the intervention. The lower NPI and A-trait scores are consistent with a more confident posture and less pessimistic view by caregivers after the intervention. The study also revealed that caregivers who provided care without help from others were more optimistic after the intervention program and that caregivers who spoke to the physician about the diagnoses of their relatives also responded by emphasizing the problem when facing stressful situations, showing that the absence of information leads to greater timidity and beliefs to explain what is happening with the demented patient.

Caregivers who were daughters and sons of patients with dementia had greater benefits from the intervention in reducing anxiety compared to patient spouses. $\mathrm{Croog}^{29} \mathrm{ob}-$ served that the effect of spouse illness on relationships and social participation of the couple contributes more to the emergence or worsening of depression and anxiety in caregivers than to other stressors.

Other factors may be taken into account. Caregivers with no income showed greater reduction in stress symptoms and achieved higher QoL levels. The intervention has been shown to benefit caregivers who had no income and who initially had little access to information about the disease. Moreover, after the intervention, less experienced individuals began to deal with difficult situations by focusing more on the problem than more experienced caregivers. In fact, these former caregivers showed greater reduction in ZBI and experienced less stress, being able to focus more on problems.

The level of information was also responsible for a more significant difference in QoL. Therefore, misinformation seems to influence the perception of well-being and security. Income is also related to the functional level of the patient. A linear relationship was observed between caregiver income and patient capacity and independence in activities of daily living. More economically advantaged families have means to provide the elderly with more exclusive and modern treatment, with access to multidisciplinary teams, as well as supplying equipment that makes the environment more accessible to dependent individuals.

Concerning caregiver QoL, higher income and greater age were found to be disadvantageous with regard to well-being. Caregivers financially better had a mean age of 55 years, an active professional life and depended on their jobs as their main income source. It is reasonable to assume that these individuals feel overworked and stressed amid work commitments, 
family life and the caregiver role. With regard to age, older caregivers are more prone to stress overload, dealing with multiple concerns about well-being, the illness and their own health.

The main limitations of this study are the small sample size and the lack of a control group. The investigation was carried out at a university center of tertiary care and was specifically designed for caregivers and patients who regularly attended the clinic. The study length was limited to the research time available, which partially explains the small sample.

In conclusion, the CBT program was effective for alleviating the adverse effects on the caregivers' QoL. The intervention seemed to relieve anxiety levels and tended to reduce depressive symptoms presented by the caregivers at the beginning of the study. Moreover, the perception of caregivers changed in relation to QoL and neuropsychiatric symptoms of dementia patients. Lastly, although the perception of burden by caregivers remained high, there were indications that the intervention time was overly short to impact this factor. We believe that future and longer studies can provide further information which might serve to improve support for caregivers, especially in developing countries.

\section{References}

1. Zarit SH, Todd PA, Zarit JM. Subjective burden of husbands and wives as caregivers: a longitudinal study. Gerontologist 1986;26:260-266.

2. Brodaty H, Mittelman M, Gibson L, Seeher K, Burns A. The effects of counseling spouse caregivers of people with Alzheimer disease taking donepezil and of country of residence on rates of admission to nursing homes and mortality. Am J Geriatr Psychiatry 2009;17:734-743.

3. Mittelman MS, Ferris SH, Shulman E, Steinberg G, AmbinderA, Mackell JA, et al. A comprehensive support program: effect on depression in spouse-caregivers of AD patients. Gerontologist 1995;35:792-802.

4. Hinchliffe AC, Hyman IL, Blizard B, Livingstone G. Behavioural complications of dementia - can they be treated? Internat J Geriatr Psychiatry 1995;10:839-847.

5. Mittelman MS, Roth DL, Coon DW, Haley WE. Sustained benefit of supportive intervention for depressive symptoms in caregivers of patients with Alzheimer's disease. Am J Psychiatry 2004;161:850-856.

6. Gaugler JE, Roth DL, Haley WE, Mittelman MS. Can counseling and support reduce burden and depressive symptoms in caregivers of people with Alzheimer's disease during the transition to institutionalization? Results from the New York University caregiver intervention study. J Am Geriatr Soc 2008; 56:421-428.

7. Elliott AF, Burgio LD, Decoster J. Enhancing caregiver health: findings from the resources for enhancing Alzheimer's caregiver health II intervention. J Am Geriatr Soc 2010;58:30-37.

8. Prince MJ, Acosta D, Castro-Costa E, Jackson J, Shaji KS. Packages of care for dementia in low - and middle-income countries. PLoS Med 2009;6:e1000176.

9. Prince M, Ferri CP, Acosta D, Albanese E, Arizaga R, Dewey M, et al. The protocols for the 10/66 dementia research group population-based research programme. BMC Public Health 2007;7:165.

10. Dias A, Dewey ME, D'Souza J, Dhume R, Motghare DD, Shaji KS, et al. The effectiveness of a home care program for supporting caregivers of persons with dementia in developing countries: a randomised controlled trial from Goa, India. PLoS One 2008;3:e2333.

11. Gavrilova SI, Ferri CP, Mikhaylova N, Sokolova O, Banerjee S, Prince M. Helping carers to care - the 10/66 dementia research group's randomized control trial of a caregiver intervention in Russia. Int $\mathrm{J}$ Geriatr Psychiatry 2008;24:347-354.

12. Guerra M, Ferri CP, Fonseca M, Banerjee S, Prince M. Helping carers to care: the 10/66 dementia research group's randomized control trial of a caregiver intervention in Peru. Rev Bras Psiquiatr 2011;33:47-54.

13. Foss MP, Lange C, Filho JHS, Brunini F, Vale FAC. Support groups for caregivers of patients with Dementia: a comparative study. Dementia Neuropsychologia 2007;2:196-202.

14. American Psychiatric Association. Diagnostic and Statistical Manual of Mental Disorders. $4^{\text {th }}$ ed (DSM-IV). Washington, DC: American Psychiatric Association; 2000.
15. Brucki SMD, Nitrini R, Caramelli P, Bertolucci PHF, Okamoto IH. Sugestões para o uso do mini-exame do estado mental no Brasil. Arq Neuropsiquiatr 2003;61:777-781.

16. Carthery-Goulart MT, Areza-Fegyveres R, Schultz RR, Okamoto I, Caramelli P, Bertolucci PH, et al. Adaptação transcultural da Escala de Avaliação de Incapacidade em Demência (Disability Assessment for Dementia - DAD). Arq Neuropsiquiatr 2007;65:916-919.

17. Camozzato AL, Kochhann R, Simeoni C, Konrath CA, Pedro Franz A, Carvalho A, et al. Reliability of the Brazilian Portuguese version of the Neuropsychiatric Inventory (NPI) for patients with Alzheimer's disease and their caregivers. Int Psychogeriatr 2008;20:383-393.

18. Novelli MM, Rovere HH, Nitrini R, Caramelli P. Cross-cultural adaptation of the quality of life assessment scale on Alzheimer disease. Arq Neuropsiquiatr 2005;63:201-206.

19. Novelli MMPC, Nitrini R, Caramelli P.Validation of the Brazilian version of the quality of life scale for patients with Alzheimer's disease and their caregivers (QOL-AD). Aging Ment Health 2010;14:624-631.

20. Taub A, Andreoli SB, Bertolucci PH. Dementia caregiver burden: reliability of the Brazilian version of the Zarit caregiver burden interview. Cad Saude Publica 2004;20:372-376.

21. Ferreira EAG, Marques AP, Matsutani LA, Vasconcellos EG, Mendonça LLF. Avaliação da dor e estresse em pacientes com fibromialgia. Rev Bras Reumatol 2002;42:104-110.

22. de Souza-Talarico JN, Chaves EC, Nitrini R, Caramelli P. Stress and coping in older people with Alzheimer's disease. J Clin Nurs 2008;18:457-465.

23. Spielberger CD, Gorsuch RL, Lushene RE. IDATE: Inventário de Ansiedade Traço-Estado. 2a. ed. Traduzido e adaptado por Biaggio A \& Natalício L. Departamento de Estudos do CEPA, Rio de Janeiro; 2003.

24. Amorim P. Mini International Neuropsychiatric Interview (M.I.N.I.): validação de entrevista breve para diagnóstico de transtornos mentais. Rev Bras Psiquiatr 2000;22:106-115.

25. Caballo VE. Manual de Técnicas de Terapia e Modificação do Comportamento. São Paulo: Livraria Santos Editora; 2002.

26. McKhann G, Drachman D, Folstein M, Katzman R, Price D, Stadlna EM. Clinical diagnosis of Alzheimer's disease: report of the NINCDS-ADRDA Work Group under the auspices of Department of Health and Human Services Task Force on Alzheimer's disease. Neurology 1984;34:939-944.

27. Román GC, Tatemichi TK, Erkinjuntti T, Cummings JL, Masdeu JC, Garcia JH, et al. Vascular dementia: diagnostic criteria for research studies. Report of the NINDS-AIREN International Workshop. Neurology 1993;43:250-260.

28. Lazarus R, Folkman S. Stress, appraisal, and coping. New York: Spring Publishing Company; 1984.

29. Croog SH, Burleson JA, Sudilovsky A, Baume RM. Spouse caregivers of Alzheimer patients: problem responses to caregiver burden. Aging Ment Health 2006;10:87-100. 